\title{
Texture of the Freshwater Shells from the Unionidae Family Collected in the Czech Republic Investigated by X-ray and Neutron Diffraction
}

\author{
Monika Kučeráková 1,*(D), Jan Rohlíček ${ }^{2}$, Stanislav Vratislav ${ }^{1} \mathbb{D}$, Markéta Jarošová ${ }^{2} \mathbb{D}$, Ladislav Kalvoda $^{1} \mathbb{D}$, \\ Dmitry Nikolayev $^{3}$, Tatiana Lychagina ${ }^{3}$ (D) and Karel Douda ${ }^{4}$
}

check for updates

Citation: Kučeráková, M.; Rohlíček, J.; Vratislav, S.; Jarošová, M.; Kalvoda, L.; Nikolayev, D.; Lychagina, T.; Douda, K. Texture of the Freshwater Shells from the Unionidae Family Collected in the Czech Republic Investigated by $\mathrm{X}$-ray and Neutron Diffraction. Crystals 2021, 11, 1483. https://doi.org/10.3390/ cryst11121483

Academic Editor: José L. Arias

Received: 25 October 2021

Accepted: 27 November 2021

Published: 30 November 2021

Publisher's Note: MDPI stays neutral with regard to jurisdictional claims in published maps and institutional affiliations.

Copyright: (c) 2021 by the authors. Licensee MDPI, Basel, Switzerland. This article is an open access article distributed under the terms and conditions of the Creative Commons Attribution (CC BY) license (https:// creativecommons.org/licenses/by/ $4.0 /)$.
1 Department of Solid State Engineering, Faculty of Nuclear Sciences and Physical Engineering, Czech Technical University in Prague, 11519 Prague, Czech Republic; stanislav.vratislav@fjfi.cvut.cz (S.V.); ladislav.kalvoda@fjfi.cvut.cz (L.K.)

2 Department of Structure Analysis, Institute of Physics, Czech Academy of Sciences, 18221 Prague, Czech Republic; rohlicek@fzu.cz (J.R.); jarosova@fzu.cz (M.J.)

3 Frank Laboratory of Neutron Physics, Joint Institute for Nuclear Research, 141980 Dubna, Russia; dmitry@nf.jinr.ru (D.N.); lychagina@jinr.ru (T.L.)

4 Department of Zoology and Fisheries, Faculty of Agrobiology, Food and Natural Resources, Czech University of Life Sciences Prague, 16521 Prague, Czech Republic; doudak@af.czu.cz

* Correspondence: monika.kucerakova@fjfi.cvut.cz

\begin{abstract}
Bivalve shells exhibit extreme mechanical resistance despite using a minimal amount of material. The shells thus represent an inspiration and a source of information for environmental, geological, and engineering sciences. In this study, two species of freshwater shells from the Unionidae family, collected in the Czech Luznice River, were investigated with respect to their crystallographic preferred orientation by means of X-ray and neutron diffraction. The observed texture was found to be of a strongly uniaxial type, with the strength increasing along the shell growth direction. The c-axis of aragonite does not change during growth and its alignment remains perpendicular to the outer surface of the shell.
\end{abstract}

Keywords: texture; Sinanodonta woodiana; Anodonta anatina; X-ray diffraction; neutron diffraction; TOF; preferred orientation; pole figure

\section{Introduction}

Bivalve shells have a composite structure consisting of calcium carbonate $\mathrm{CaCO}_{3}$, which can be present in three crystallographic variants_calcite, aragonite and vaterite [1] It is known that the shells of the species Sinanodonta woodiana and Anodonta anatina consist of three layers-periostracum, which is an organic protective layer, below which lies the prismatic layer and the nacre layer [2,3].

Bivalve mollusks have received a great deal of attention in many scientific fields. For example, from an ecological point of view, they are important indicators of pollution $[4,5]$. For paleontologists, they are an organism that undergoes a process of fossilization, of which we still know very little [6]. In materials engineering, shells are important patterns for the design of bioinspired material due to their unique mechanical properties [7,8].

Concerning the latter area, shells are characterized by anisotropy of physical and mechanical properties, which is closely related to the preferred crystallographic orientation (texture) of the constituent crystalline grains [9]. Therefore, the characterization of the texture and its correlation with the above-mentioned properties is a cornerstone for understanding the properties of biological polycrystalline materials [10].

Few publications have dealt with the preferred orientation of shells. The majority of the studies have examined the preferred orientation using the EBSD method. There are very few neutronographic studies in this field—see [10,11]. In addition, regarding some 
details, the obtained textural results are rather inconsistent-for instance, there is some discrepancy in the preferred orientation of the b- and c-axes of aragonite [12,13].

Our previous study of Sinanodonta woodiana shells showed a difference in the sharpness of the texture of the young individual and the adult shell [14]. In our further research, presented here, we address further questions related to the texture of shells: Is there a change in the texture at different points of the shell? Is there any change in the texture of shells within one family (Unionidae) of shells? According to our best knowledge, similar textural research on these invasive shells has not yet been carried out. In addition, we were also interested in the difference between the texture determined by $\mathrm{X}$-ray methods and the global neutronographic texture.

In our study, we focused on two freshwater representatives of the shells of bivalves from the Unionidae family collected from the Lužnice River, Czech Republic:

(i) Anodonta anatina (Linnaeus, 1758) is one of the most abundant species of bivalves in the Czech Republic. It inhabits most types of watercourses and is very sensitive to water pollution [15].

(ii) Sinanodonta woodiana (I. Lea, 1834) is a non-native species in the Czech Republic (and in the whole of Europe), and is spreading to an increasing number of localities and thus oppressing the original species [16]. This species is also very sensitive to water pollution and is an indicator of water purity [17].

\section{Materials and Methods}

X-ray texture measurements of the nacreous layer were performed on a SmartLab Rigaku X-ray diffractometer (with $\mathrm{Cu} \mathrm{K} \alpha$ rotating anode) located at the Institute of Physics of the Academy of Sciences of the Czech Republic. Pole figures of crystallographic planes (111), (021), (002), (211), (220) and (221) were extracted from the measured X-ray diffraction diagrams. Texture data processing was performed using the SmartLab Studio II v4.4.208.0 software package from Rigaku. Complete pole figures were calculated using the orientation distribution function (ODF) of the WIMV method [18].

The global texture of the shells was determined by neutron diffraction. Both constant wavelength and time-of-flight (TOF) methods were used. The measurements with monochromatic neutrons were performed on a KSN-2 diffractometer in the Laboratory of Neutron Diffraction (located at the Nuclear Research Institute Rez plc, Rez, Czech Republic) of the Department of Solid State Engineering, FNSPE CTU in Prague. TOF measurements were performed on a SKAT diffractometer at Frank's laboratory, Joint Institute for Nuclear Research, Dubna, Russia. GSAS-II [19] and MTEX 5.7.0 [20] software packages (MATLAB 9.4) were used to analyze neutronographic data from lambda constant method measurements. Pole figures from the time-of-flight measured spectra were extracted by the program Pole figures Extractor (version 1) [21-23].

Note that the penetration of neutrons is significantly higher (up to millimeters) [24]. Therefore, the observed neutronographic results represent a global texture of the shells. The X-ray diffraction results, by comparison, show the preferred orientation of only the inner nacreous layer (local texture).

Table 1 summarizes the experimental method applied to the particular shell type. As we previously showed [14], shell species studied here consist of the aragonite phase only, which simplifies the crystallographic texture analysis.

Table 1. Illustrative summary of methods used in the study of individual samples.

\begin{tabular}{ccc}
\hline Method & Sinanodonta woodiana & Anodonta anatina \\
\hline X-ray texture measurements & YES & YES \\
Constant wavelength & YES & YES \\
neutrons measurements & NO & YES \\
TOF neutrons measurements & \\
\hline
\end{tabular}


Shells of the species Anodonta anatina were ca. $5 \mathrm{~cm}$ long in the longest linear dimension. In the case of neutronographic measurements (for both used neutronographic methods-neutrons with constant wavelength and TOF neutrons), it was not necessary to cut the shell. In the case of X-ray measurements, a square sample with a side length of about $1.5 \mathrm{~cm}$ was then taken from upper part of the shell.

Four samples (square shape with the edge length of about $1.5 \mathrm{~cm}$ ) were then also cut from the shells of the species Sinanodonta woodiana (the original length of the shells was about $16 \mathrm{~cm}$ - see Figure 1) in order to map the texture development across the shell. For neutronographic measurements (neutrons with a constant wavelength), a square sample with edge of about $5 \mathrm{~cm}$ was then taken from the shell.

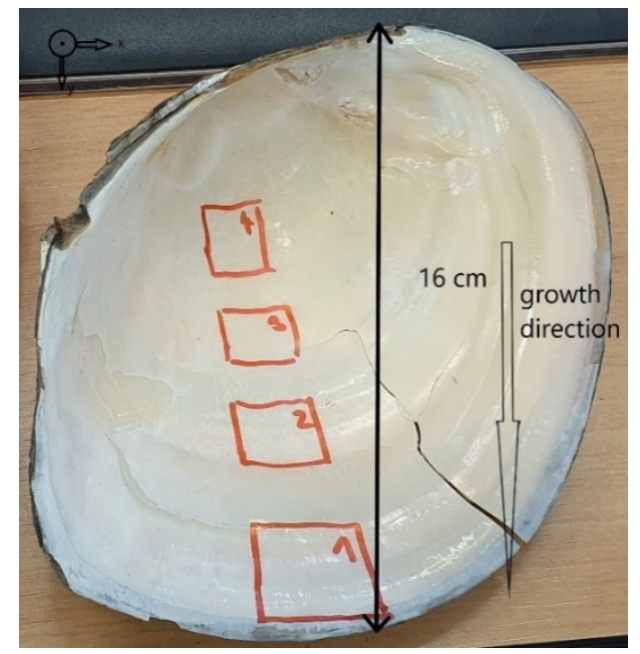

Figure 1. Shell of the species Sinanodonta woodiana with the marked sampling areas for X-ray texture analysis. In addition, the growth direction is indicated. The direction of growth is identical to the direction of sequence $4,3,2,1$.

\section{Results}

Figure 2 shows ODF sections at $\Phi=90^{\circ}$ for both species. Complete $X$-ray pole figures of nacreous layer observed for both species (Sinanodonta woodiana and Anodonta anatina) for planes (100), (010) and (001) are shown in Figure 3. Figure 4 then shows, for both shell species, the neutronographic pole figures (002) and (102) measured by the neutron diffraction methods used.

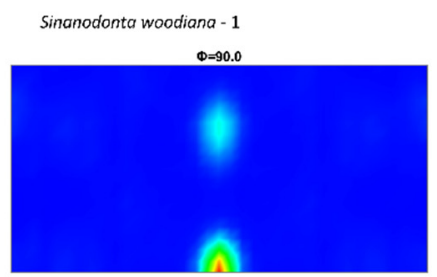

Sinonodonta woodiana - 4

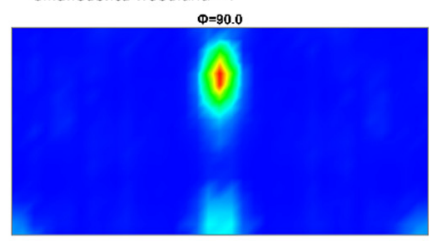

Sinonodonta woodiana - 2

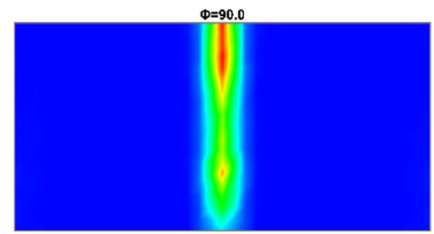

Anodonto anatina

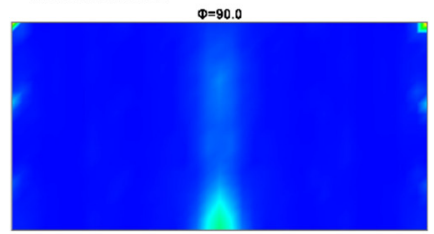

Sinanodonta woodiana -3
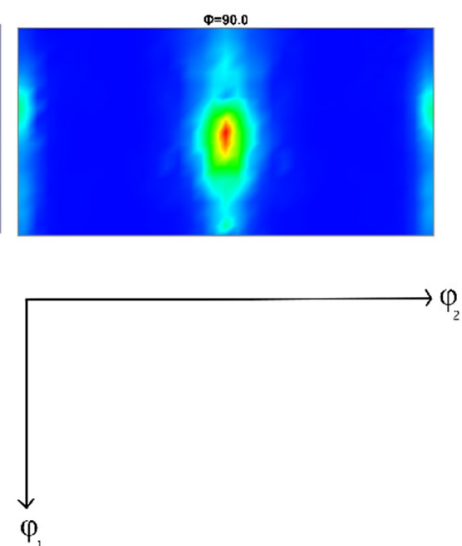

Figure 2. ODF sections $\left(\Phi=90^{\circ}\right)$ calculated from XRD pole figures for Sinanodonta woodiana (four investigated areas $1-4$, cf. Figure 1) and Anodonta anatina (upper part of the shell) samples. The angles $\varphi_{1}$ and $\varphi_{2}$ vary within $0-90^{\circ}$ and $0-180^{\circ}$, respectively. 


\section{(100)}

(010)

$(001)$

\section{Sinanodonta woodiana}
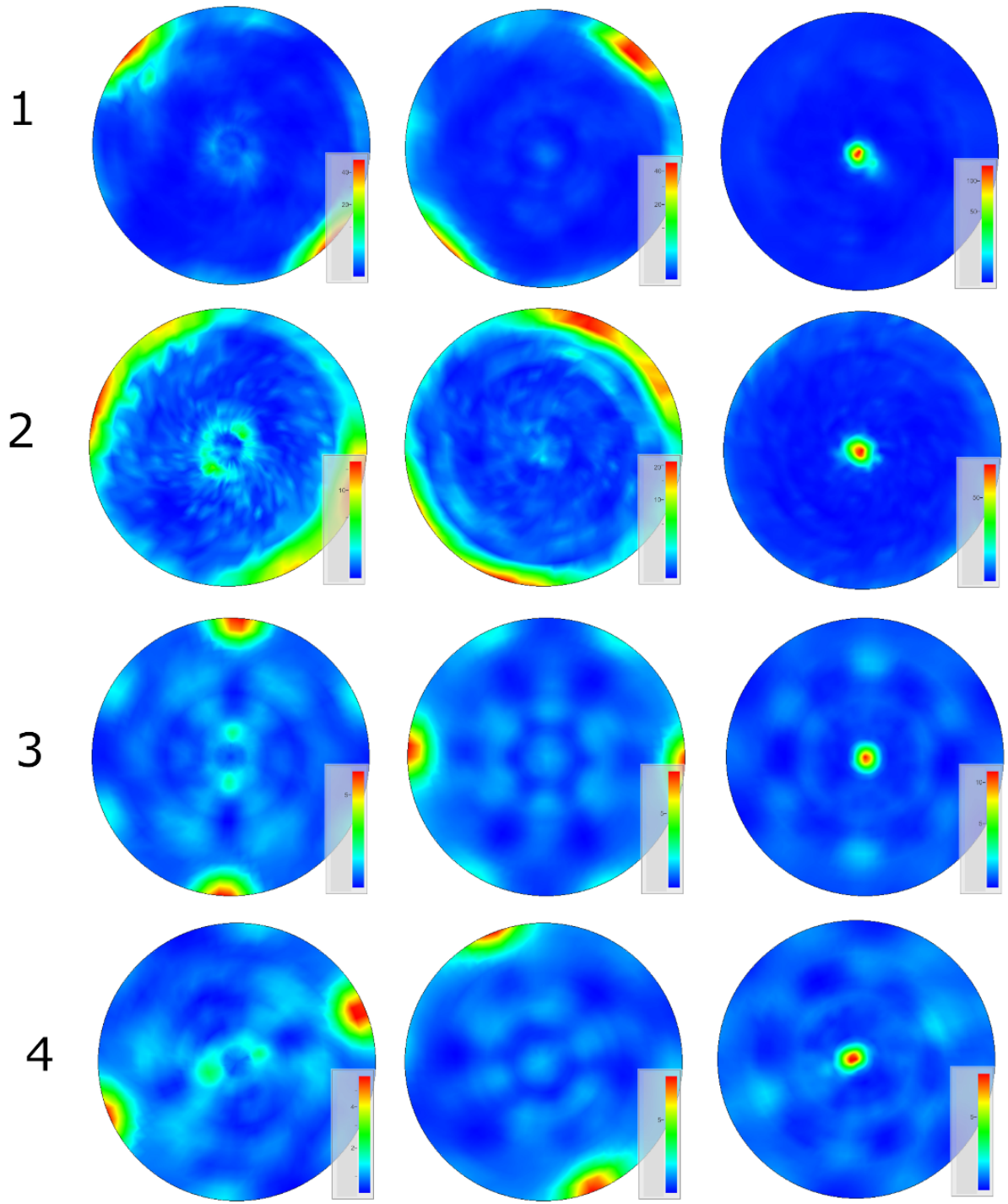

\section{Anodonta anatina}
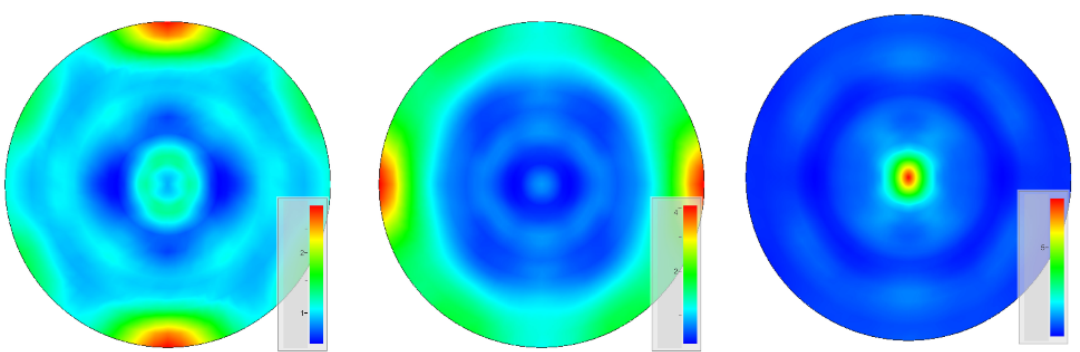

Figure 3. Complete pole figures (100), (010) and (001) obtained from X-ray diffraction measurements for the indicated mollusk samples. Center and top of the pole figure, respectively, corresponds to the normal direction and growth direction of the shell. 


\section{Sinanodonta woodiana}

(002)
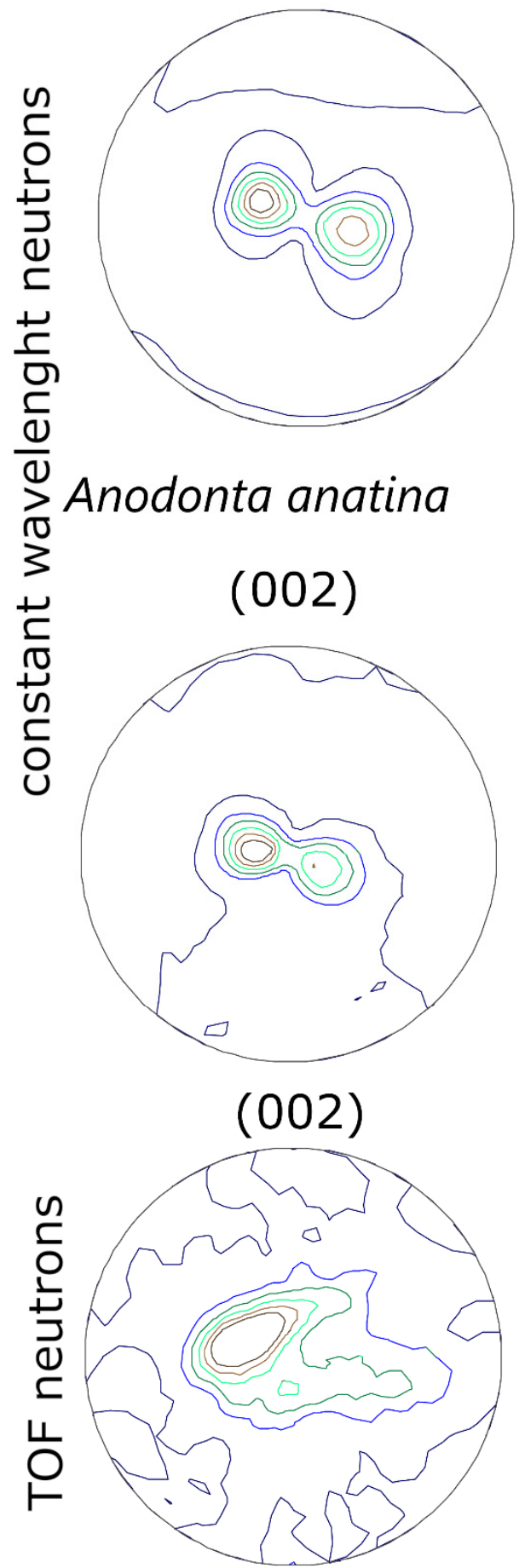

$(102)$

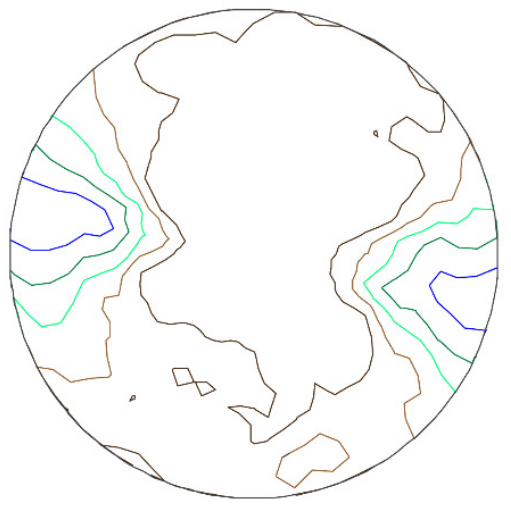

(102)

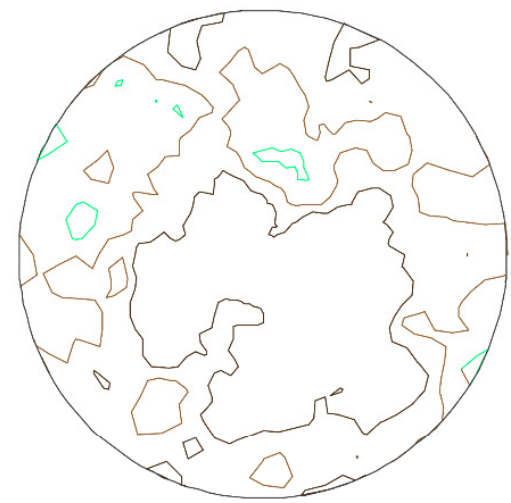

$(200)+(102)$

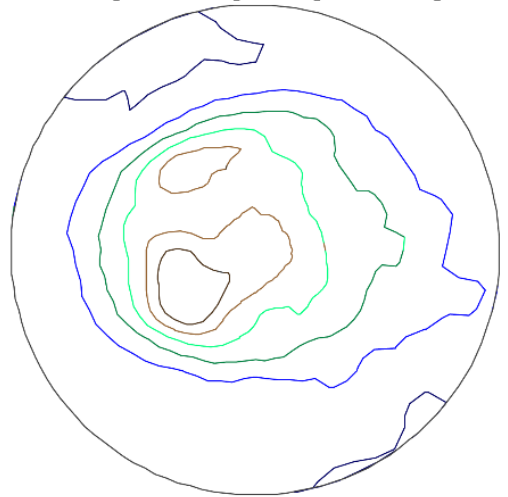

Figure 4. Full pole figures (002) and (102) measured by the indicated neutron diffraction method for the studied mollusk samples. In case of the TOF method, only superposition of (200) and (102) pole figures could be obtained.

\section{Discussion}

In agreement with the results of previous studies $[10,11,25,26]$, it follows from both X-ray and neutron diffraction pole figures shown in Figures 3 and 4 that the c-axis of aragonite grains is preferentially oriented parallel to the surface normal of the shells for 
both studied species. The preferential orientation demonstrates itself by a sharp central maximum in (001) pole figures.

In particular, for the texture evolution of Sinanodonta woodiana studied in detail along the positions 1-4 (Figure 1), we observe that this maximum widens slightly when moving from 1 to 4 (Figure 3). This effect corresponds to a slight deviation from the pure fiber texture when moving along the shell surface in the direction opposite to the direction of shell growth. The latter result is in concert with the global texture data obtained by neutron diffraction methods (Figure 4). The results obtained by both applied neutron methods for both studied shell species are similar, showing similar global texture maxima, and confirming the mentioned slight deviation from the ideal fiber texture deduced from the $\mathrm{X}$-ray pole figures.

A re-orientation of poles to $\{010\}$ planes is evident with the Sinanodonta woodiana shell growth, starting from the direction almost parallel to the growth direction, gradually changing to the perpendicular orientation, and returning to the parallel orientation (Figure 3). ODF sections shown in Figure 2 confirm the presence of fiber texture in all tested areas (1 to 4) of Sinanodonta woodiana shell, and demonstrate its texture evolution with the shell growth by the observed ODF maximum shift along the identified fiber texture component.

We can see that the nacre of Sinanodonta woodiana is not always perfectly aligned along the entire shell (Figure 3). We even observe that the b- and c-axes of aragonite rotate along the direction of shell growth. This observation contradicts the results found in [25]. In this publication, the authors studied the textures of five Unionidae bivalves. They found that the axis of aragonite is parallel to the growth direction. In our case, the strongest alignment of the b-axis in the direction of shell growth is observed in area 3. The deviation from the perfectly aligned structure is less than $10^{\circ}$.

When assessing the texture strength, we can use the pole maximum value in (001) pole figures in place of characteristics. Regarding this parameter, we see that for the tested Sinanodonta woodiana samples, there is a strong growing tendency along the growth direction. At the point 4 , the maximum value amounts to ca. 5 m.r.s., and growth towards the point 1 reaches ca. 100 m.r.s. (Figure 3). Thus, the observed texture strength increases ca. 20-fold along the analyzed growth path.

The features characteristic for the Sinanodonta woodiana texture hold also for the preferred orientation of the Anodonta anatina sample. The observed texture is again of a fiber texture type with the c-axis perpendicular to the shell surface. The maximum value obtained for the (001) pole figure amounts to ca. 5 , this value being in good agreement with the value found at the testing point 4 of the Sinanodonta woodiana shell. The (001) confirms the global fiber texture similarity between the two tested species' pole figures obtained from neutron diffraction (Figure 4) and ODF sections (Figure 2). However, as suggested by other pole figures (Figures 3 and 4), the mentioned agreement apparently does not hold for the details of preferential orientation of grains along the texture axis. The significance and statistical reproducibility of these texture details in relation to the selected shell species will be the subject of further research.

\section{Conclusions}

From X-ray measurements of the nacre, we found that during the growth of the shell of the species Sinanodonta woodiana, the a and b directions of aragonite are reoriented. Conversely, the direction of the c-axis does not change during growth and its alignment remains perpendicular to the outer surface of the shell.

The latter statement was also confirmed by neutronographic measurements.

A detailed scan of the crystallographic texture evolution along the shell growth direction performed for the Sinanodonta woodiana sample revealed that the texture strength grows with the shell growth, the observed ratio of the increase in the texture strength amounts to ca. 20, and changes in the orientation distribution involving the rotation of grains occur along the texture fiber axis. Further research into these effects is required. 
For Anodonta anatina, which belongs to the same family, we confirmed that the c-axis of aragonite is also oriented perpendicular to the outer surface of the shell. The texture strength of both species is comparable and corresponds to the sampling site.

Author Contributions: Conceptualization, M.K. and L.K.; methodology, K.D., T.L. and D.N.; software, D.N. and J.R.; data curation, S.V., D.N. and T.L.; formal analysis, M.K., S.V., J.R., D.N., M.J. and T.L.; investigation, M.K.; resources, K.D.; writing—original draft preparation, M.K.; writing—review and editing, M.K., L.K., S.V., D.N. and T.L.; visualization, M.K., D.N., S.V., M.J.; supervision, M.K.; project administration, M.K.; funding acquisition, L.K. and M.K. All authors have read and agreed to the published version of the manuscript.

Funding: This research was funded by Ministry of Education, Youth and Sports, Czech Republic, grant number CZ.02.1.01/0.0/0.0/16_019/0000778, and the Czech Republic-JINR grants, grant number 182/18.03.2021 and grant number 181/18.03.2021.

Institutional Review Board Statement: Not applicable.

Informed Consent Statement: Not applicable.

Data Availability Statement: The data supporting reported results can be obtained on request from the article authors.

Conflicts of Interest: The authors declare no conflict of interest. The funders had no role in the design of the study; in the collection, analyses, or interpretation of data; in the writing of the manuscript, or in the decision to publish the results.

\section{References}

1. Mayer, G. Rigid Biological Systems as Models for Synthetic Composites. Science 2005, 310, 1144-1147. [CrossRef]

2. Kalesaran, O.J.; Lumenta, C. Analysis of Scanning Electron Microscopy on Sinanodonta (Anodonta) woodiana Nacre (Lea, 1834). J. Aquac. Fish Health 2021, 10, 75-84. [CrossRef]

3. Freer, A.; Greenwood, D.; Chung, P.; Pannell, C.L.; Cusack, M. Aragonite Prism-Nacre Interface in Freshwater Mussels Anodonta anatina (Linnaeus, 1758) and Anodonta cygnea (L. 1758). Cryst. Growth Des. 2010, 10, 344-347. [CrossRef]

4. Wilson, W.A.; Fritts, A.K.; Fritts, M.W.; Unrine, J.M.; Casper, A.F. Freshwater mussel (Unionidae) shells document the decline of trace element pollution in the regional watersheds of Chicago (Illinois, USA). Hydrobiologia 2018, 816, 179-196. [CrossRef]

5. Palpandi, C.; Kesavan, K. Heavy metal monitoring using Nerita crepidularia-mangrove mollusc from the Vellar estuary, Southeast coast of India. Asian Pac. J. Trop. Biomed. 2012, 2, S358-S367. [CrossRef]

6. Whitehead, J.M.; Ehrmann, W.; Harwood, D.M.; Hillenbrand, C.D.; Quilty, P.G.; Hart, C.; Taviani, M.; Thorn, V.; McMinn, A. Late Miocene paleoenvironment of the Lambert Graben embayment, East Antarctica, evident from: Mollusc paleontology, sedimentology and geochemistry. Glob. Planet. Chang. 2006, 50, 127-147. [CrossRef]

7. Meyers, M.A.; Lin, A.; Chen, P.Y.; Muyco, J. Mechanical strength of abalone nacre: Role of the soft organic layer. J. Mech. Behav. Biomed. Mater. 2008, 1, 76-85. [CrossRef] [PubMed]

8. Wenk, H.-R.; Houtte, P. Texture and anisotropy. Rep. Prog. Phys. 2004, 67, 1367-1428. [CrossRef]

9. Bunge, H.-J. Texture Analysis in Materials Science: Mathematical Methods, 1st ed.; Akademie-Verlag: Berlin, Germany, 1969; ISBN 0-408-10642-5.

10. Frýda, J.; Klicnarová, K.; Frýdová, B.; Mergl, M. Variability in the crystallographic texture of bivalve nacre. Bull. Geosci. 2010, 85, 645-662. [CrossRef]

11. Chateigner, D.; Hedegaard, C.; Wenk, H.R. Mollusc shell microstructures and crystallographic textures. J. Struct. Geol. 2000, 22, 1723-1735. [CrossRef]

12. Nikolayev, D.; Lychagina, T.; Pakhnevich, A. Experimental neutron pole figures of minerals composing the bivalve mollusc shells. SN Appl. Sci. 2019, 1, 344. [CrossRef]

13. Nekhoroshkov, P.; Zinicovscaia, I.; Nikolayev, D.; Lychagina, T.; Pakhnevich, A.; Yushin, N.; Bezuidenhout, J. Effect of the Elemental Content of Shells of the Bivalve Mollusks (Mytilus galloprovincialis) from Saldanha Bay (South Africa) on Their Crystallographic Texture. Biology 2021, 10, 1093. [CrossRef] [PubMed]

14. Kucerakova, M.; Rohlicek, J.; Vratislav, S.; Nikolayev, D.; Lychagina, T.; Kalvoda, L.; Douda, K. Texture Study of Sinanodonta Woodiana Shells by X-Ray Diffraction. J. Surf. Investig. X-Ray Synchrotron Neutron Tech. 2021, 15, 640-643. [CrossRef]

15. Ugge GM, O.E.; Jonsson, A.; Olsson, B.; Sjöback, R.; Berglund, O. Transcriptional and biochemical biomarker responses in a freshwater mussel (Anodonta anatina) under environmentally relevant Cu exposure. Environ. Sci. Pollut. Res. 2020, 27, 9999-10010. [CrossRef]

16. Bódis, E.; Tóth, B.; Szekeres, J.; Borza, P.; Sousa, R. Empty native and invasive bivalve shells as benthic habitat modifiers in a large river. Limnologica 2014, 49, 1-9. [CrossRef] 
17. Liu, Y.; Hao, A.; Iseri, Y.; Li, C.; Zhang, Z.; Kuba, T. The Evaluation of Sinanodonta Woodiana Application Feasibility As a Microcystis-Blooming Removal Tool In Microcosm Experiments. J. Jpn. Soc. Civ. Eng. Ser. G (Environ. Res.) 2013,69, III_45-III_53. [CrossRef]

18. Matthies, S. 20 Years WIMV, History, Experience and Contemporary Developments. Mater. Sci. Forum 2002, 408-412, 95-100. [CrossRef]

19. Toby, B.H. EXPGUI, a graphical user interface for GSAS. J. Appl. Crystallogr. 2001, 34, 210-213. [CrossRef]

20. Krakow, R.; Bennett, R.J.; Johnstone, D.N.; Vukmanovic, Z.; Solano-Alvarez, W.; Lainé, S.J.; Einsle, J.F.; Midgley, P.A.; Rae, C.M.F.; Hielscher, R. On three-dimensional misorientation spaces. Proc. R. Soc. A Math. Phys. Eng. Sci. 2017, 473. [CrossRef] [PubMed]

21. Nikolayev, D.I.; Lychagina, T.A.; Nikishin, A.V.; Yudin, V.V. Investigation of measured pole figures errors. Mater. Sci. Forum 2005, 495-497, 307-312. [CrossRef]

22. Lychagina, T.; Nikolayev, D.; Wagner, F. Using individual spectra simulation for the study of pole figures errors. Texture Stress Microstruct. 2009, 2009, 237485. [CrossRef]

23. Lychagina, T.; Nikolayev, D. Investigation of experimental pole-figure errors by simulation of individual spectra. Crystallogr. Rep. 2007, 52-55, 774. [CrossRef]

24. Furrer, A.; Mesot, J.; Strässle, T. Neutron Scattering in Condensed Matter Physics; Series on Neutron Techniques and Applications; World Scientific: Singapore, 2009. [CrossRef]

25. Checa, A.G.; Rodriguez-Navarro, A. Geometrical and crystallographic constraints determine the self-organization of shel microstructures in Unionidae (Bivalvia: Mollusca). Proc. R. Soc. Lond. Ser. B Biol. Sci. 2001, 268, 771-778. [CrossRef] [PubMed]

26. Checa, A.G.; Pina, C.M.; Osuna-Mascaró, A.J.; Rodríguez-Navarro, A.B.; Harper, E.M. Crystalline organization of the fibrous prismatic calcitic layer of the Mediterranean mussel Mytilus galloprovincialis. Eur. J. Mineral. 2014, 26, 495-505. [CrossRef] 